\section{Caspase-3 Colorimetric Assay}

BioTechniques 33:1196-1197 (December 2002)

The commonly used ApoAlert caspase- 3 colorimetric assay kit detects a cleaved chromophore p-nitroanilide (pNA), after cleavage from a labeled substrate DEVD-pNA (1-6). The kit was used for murine bone marrow-derived mast cells (3) and human Burkitt lymphoma (Daudi) cells (5) with apoptosis induced by cytokine depletion and antisense p21 transfection, respectively. In comparison to the uninduced level, a 3.3 -fold (3) or 5-fold (5) increase of caspase- 3 activity was observed in the induced samples. According to the product analysis certificate, a minimum of 3-fold increase in caspase-3 activity was detected after induction of Jurkat cells in which apoptosis was induced by $40 \mu \mathrm{M}$ actinomycin $\mathrm{D}$ for $15 \mathrm{~h}$ in comparison to uninduced controls. In our study with breast cancer cells and arsenite-induced apoptosis, we obtained a less than 3-fold increase. Suspecting that an unknown reaction product interfered with the spectrophotometric detection of the pNA at 405 $\mathrm{nm}$, we developed a modified procedure that increases the sensitivity of the kit for our arsenite-induced breast cancer cells. The procedure was modified to the following: after incubation of the reaction at $37^{\circ} \mathrm{C}$ for $1 \mathrm{~h}$, the reactions

Table 1. Caspase-3 Activity in Jurkat Cell Extracts

\begin{tabular}{|lccc|}
\hline & \multicolumn{2}{c}{ Caspase Activity Units $(\overline{\mathbf{x}} \pm \mathrm{SEM})$} & \\
\cline { 2 - 3 } & Uninduced & Induced & Fold Increase \\
\hline Unboiled & $2.98 \pm 0.11$ & $7.10 \pm 0.18$ & 2.38 \\
Boiled & $0.40 \pm 0.05$ & $4.28 \pm 0.15$ & 10.70 \\
Boiled/Unboiled & & 4.49 \\
Values of caspase-3 activity, $1 \mathrm{U}=1 \mathrm{nmol} \mathrm{pNA} / \mathrm{h}$ at $37^{\circ} \mathrm{C}$. The increase in protease \\
activity was determined by comparing the induced results with the uninduced con- \\
trol sample. There is a 5-fold increase in caspase-3 activity in the boiled versus un- \\
boiled method. The values present the $\overline{\mathrm{x}} \pm \mathrm{SEM}$ of three observations. \\
\hline
\end{tabular}

were boiled at $100^{\circ} \mathrm{C}$ for $5 \mathrm{~min}$ and then centrifuged at $20000 \times g$ for 10 min to precipitate debris. Caspase activity was determined spectrophotometrically at $405 \mathrm{~nm}$ by measurement of the free pNA produced by cleavage of the substrate in the supernatant. Quantitation of pNA was determined by comparison to a pNA standard curve. Data are expressed as the $\overline{\mathrm{x}} \pm$ SEM derived from three separate experiments.

The pNA calibration curve generated with boiling is identical to the curve without boiling (Figure 1), indicating that the pNA is stable at $100^{\circ} \mathrm{C}$.

To know whether cellular extract affects the measurement of the product at $405 \mathrm{~nm}$, pNA dilutions were mixed with the extract from $2 \times 10^{6}$ Jurkat cells in each of the mixtures. The absorbance units measured (Beckman Coulter DU 640) at $405 \mathrm{~nm}$ in the unboiled sample were 0.1 higher than in the boiled sample (Figure 2). The components in the extract do not signifi- cantly affect the reading at $405 \mathrm{~nm}$.

Jurkat cells were indicated as a positive control for this kit. Apoptosis of Jurkat cells was induced by addition of $5 \mu \mathrm{M}$ camptothecin (ICN Biomedical, Costa Mesa, CA, USA) for $15 \mathrm{~h}$. A total volume of $100 \mu \mathrm{L}$ of each reaction was incubated at $37^{\circ} \mathrm{C}$ for $1 \mathrm{~h}$ in a water bath. Each sample was transferred to a small cuvette and read at $405 \mathrm{~nm}$ for detection of protease activity. Table 1 shows the induction of caspase- 3 activity. Boiling reduced the background to the extent that a greater than 10 -fold increase was obtained in the boiled induced sample. This compares to a 2fold increase in the unboiled samples or an increased sensitivity of 5-fold.

The breast cancer cell line we studied (MDA MB 468) is known to undergo apoptosis after 24-h treatment with arsenite. Using the modified procedure we have described for this kit, a 7-fold increase in caspase- 3 activity was seen in induced versus uninduced samples.

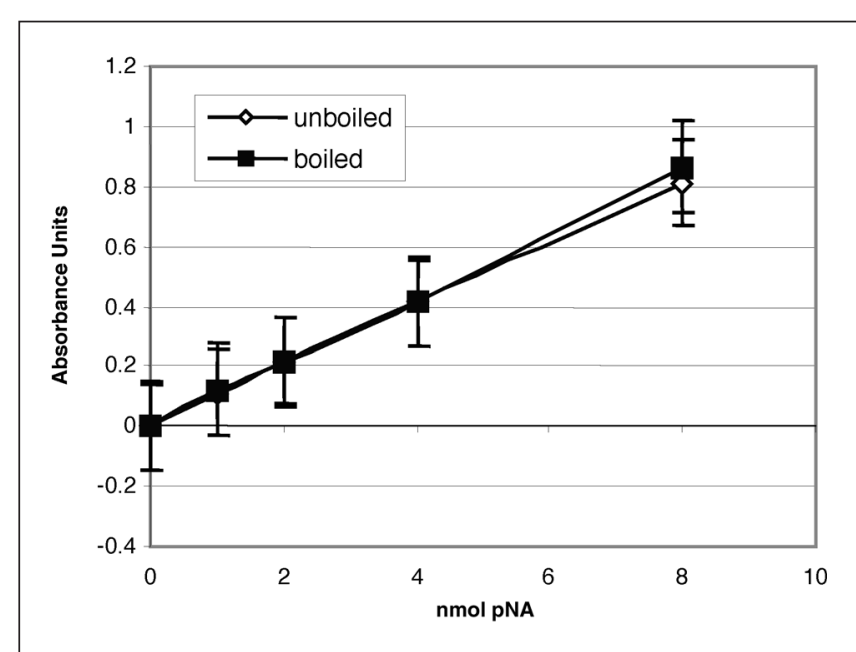

Figure 1. pNA calibration curve before and after boiling. Five dilutions of pNA were prepared, and a calibration curve generated with a spectrophotometer.

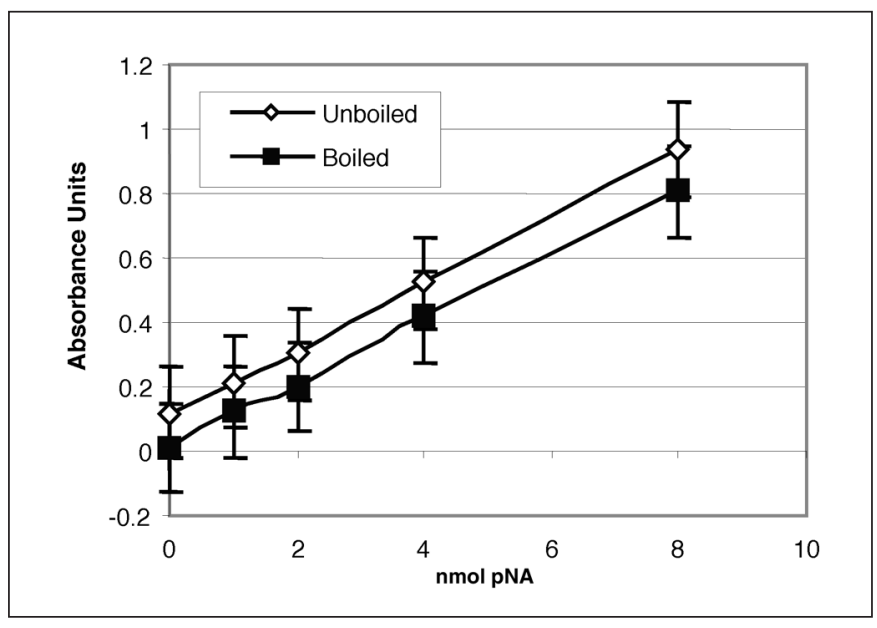

Figure 2. pNA calibration in the presence of boiled and unboiled cell extracts. pNA was mixed with cell extracts from $2 \times 10^{6}$ Jurkat cells in each dilution. The absorbance units measured in the unboiled sample were only 0.1 higher than in the boiled sample. 
This result allowed us to conclude that arsenite-induced apoptosis of this cell line was through the activation of caspase-3, although it remains unclear what reaction component(s) were modified by boiling. The mechanism of increasing sensitivity by the boiling method needs to be studied further.

\section{REFERENCES}

1.Ackermann, E.J., J.K. Taylor, R. Narayana, and C.F. Bennett. 1999. The role of antiapoptotic Bcl-2 family members in endothelial apoptosis elucidated with antisense oligonucleotides. J. Biol. Chem. 274:11245-11252.

2.Drake, R.R., T.N. Wilbert, T.A. Hinds, and K.M. Gilbert. 1999. Differential ganciclovirmediated cell killing by glutamine $125 \mathrm{mu}-$ tants of herpes simplex virus type 1 thymidine kinase. J. Biol. Chem. 274:37186-37192.

3.Fonteh, A.N., T. LaPorte, D. Swan, and M.A. McAlexander. 2001. A decrease in remodeling accounts for the accumulation of arachidonic acid in murine mast cells undergoing apoptosis. J. Biol. Chem. 276:1439-1449.

4.Janicke, R.U., P. Ng, M.L. Sprengart, and A.G. Porter. 1998. Caspase-3 is required for $\alpha$-fodrin cleavage but dispensable for cleavage of other death substrates in apoptosis. J. Biol. Chem. 273:15540-15545.

5.Marches, R., R. Hsueh, and J.W. Uhr. 1999 Cancer dormancy and cell signaling: Induction of $\mathrm{p} 21^{\text {wafl }}$ initiated by membrane IgM engagement increases survival of B lymphoma cells. Proc. Natl. Acad. Sci. USA 96:87118715.

6.Wang, S., J.A. Vrana, T.M. Bartimole, A.J. Freemerman, W.D. Jarvis, L.B. Kramer, G. Krystal, P. Dent, and S. Grant. 1997. Agents that down-regulate or inhibit protein kinase $\mathrm{C}$ circumvent resistance to 1- $\beta$-D-arabinofuranosylcytosine-induced apoptosis in human leukemia cells that overexpress Bcl-2. Mol. Pharmacol. 52:1000-1009.

Address correspondence to Dr. Lizhi Zeng, H.L. Snyder Medical Research Institute, 1407 Wheat Road, Winfield, KS 67156, USA.e-mail: lzeng@snyderrf.org

Received 17 June 2002; accepted 16 August 2002.

\section{Lizhi Zeng and Larry D. \\ Smith}

H.L. Snyder Medical Research Institute Winfield, KS, USA

\begin{tabular}{c|}
\hline For reprints of this or \\
any other article, contact \\
Reprints@BioTechniques.com
\end{tabular}

\section{Maintaining GFP Tissue Fluorescence through Bone Decalcification and Long-Term Storage}

BioTechniques 33:1197-1200 (December 2002)

Decalcification of bone is required for frozen or standard histological sectioning; however, acidic decalcification solutions abrogate the fluorescence of tissues expressing enhanced GFP. In addition, long-term storage of fluorescing tissues from in vivo studies necessitates maintaining GFP fluorescence in a solution that does not compromise tissue and cellular integrity.

The spread of metastatic cancer to skeletal sites is a grim complication frequent in breast, prostate, and lung cancers. In particular, the incidence of breast cancer metastasis to bone has been estimated to be as high as $85 \%$ (2), causing osteolytic lesions that result in pathological fractures, spinal cord compression, and hypercalcemia. Why
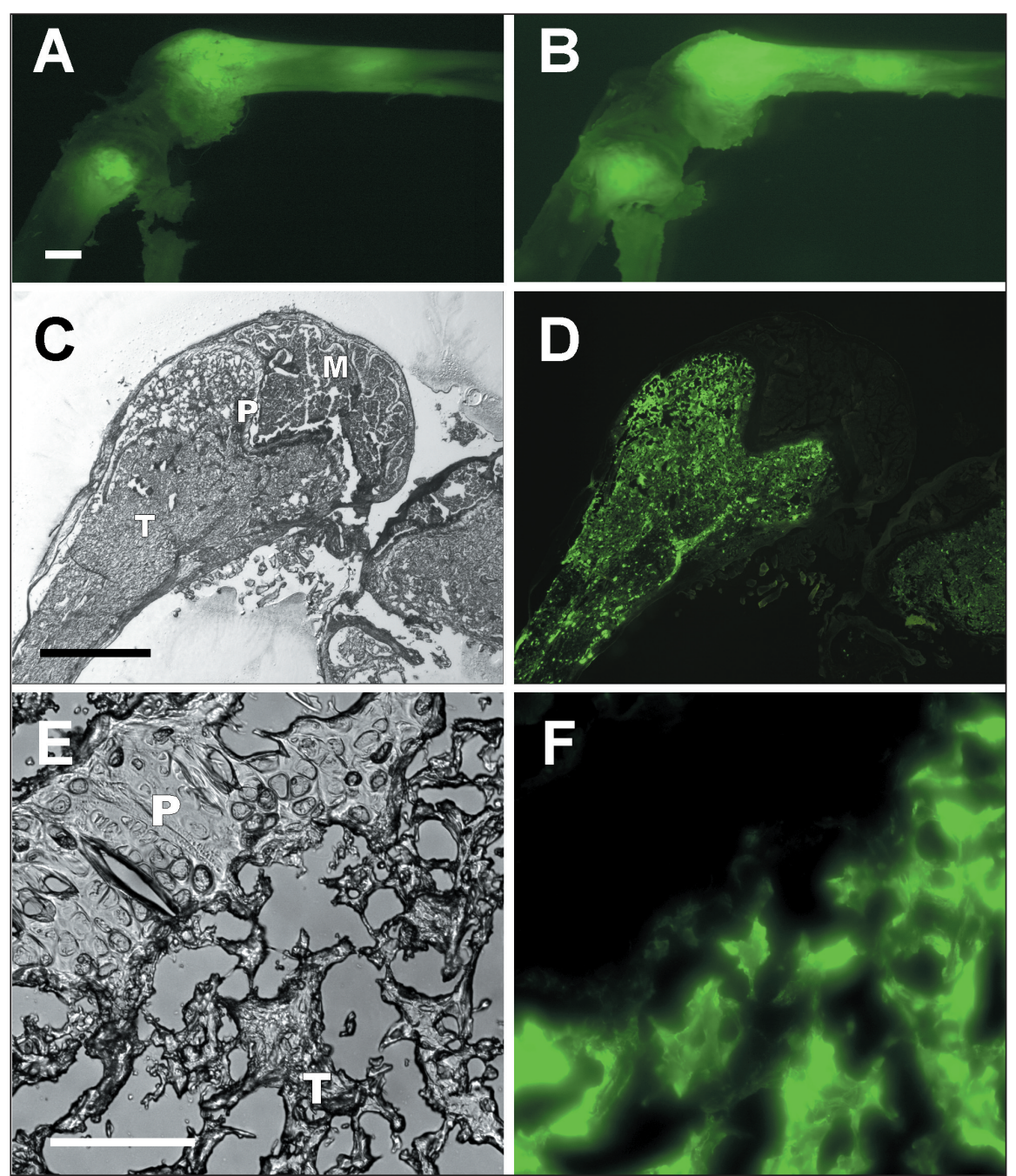

Figure 1. Fluorescence of GFP-tagged breast cancer metastases is maintained through decalcification and frozen sectioning of murine hind limb bones. (A) Fluorescence microscopy of whole femur and proximal tibia following $4 \%$ paraformaldehyde fixation. Bar $=1 \mathrm{~mm}$. (B) Fluorescence following $14 \mathrm{~h}$ incubation in 0.5 M EDTA in CMF-PBS, immediately preceding frozen sectioning. (C and E) Bright-field photomicrographs of frozen sections. Tumor $(\mathrm{T})$ has filled medullary canal but has not crossed the epiphyseal growth plate (P) into distal normal marrow (M). Since the epiphyseal growth plate is normal murine tissue, it does not fluoresce. Normal murine tissue also exists between tumor cells, and some spaces are the result of tissue sectioning artifact. $(\mathrm{C}, \mathrm{Bar}=1 \mathrm{~mm}$; E, Bar $=0.1 \mathrm{~mm})$. (D and F) Corresponding fluorescence microscopy reveals fluorescing tumor tissue replacing marrow of the medullary canal. 